\title{
Co-producing the covid-19 response in Germany, Hong Kong, Lebanon, and Pakistan
}

\author{
Robert Marten and colleagues highlight the benefits of co-production during covid-19 and call \\ for it to be become embedded in policy making
}

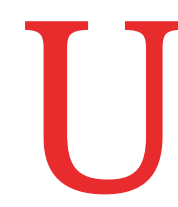

sing scientific evidence for policy making is a challenge at the best of times, but it is particularly difficult during a global pandemic. Policy makers traditionally receive inputs from health professionals and use existing evidence to develop health policies and prioritise the most effective interventions. However, in responding to the covid-19 pandemic, policy makers are often grappling with complicated decisions based on evidence that is still emerging. Even in a crisis, one way to strengthen policy making is to collaborate with researchers and other stakeholders, including the public, from the start, generating knowledge and research to inform policy through a process called co-production.

Drawing on our experiences with engaging in and observing different national responses to the covid-19 pandemic, we use examples from Germany,

\section{KEY MESSAGES}

- The covid-19 response is creating the opportunity for an accelerated and inclusive shift towards co-production for policy making

- It has brought a focus to three cross cutting issues: building on established structures; working together to coproduce research; and disseminating research and engaging communities

- The covid-19 pandemic has forced policy makers to rethink the formal and informal structures of how, where, when, and with whom they collaborate, including with researchers as well as the broader public, patients, and communities

- Unprecedented levels of public attention during the covid-19 pandemic have posed new challenges to evidence based policy making, particularly in terms of communicating sometimes complicated science and dealing with an overabundance of information
Hong Kong, Lebanon, and Pakistan to illustrate how researchers and national policy makers are applying a co-production approach. Although these examples are unique, diverse, and happening within the context of the ongoing covid19 pandemic, the findings are relevant beyond the crisis. They highlight the importance of co-production for policy making and how better to generate and use local knowledge to improve policy and management decisions. The covid-19 crisis provides an opportunity to accelerate the broader adoption of a co-production approach by focusing on three cross cutting issues: building on established structures; working together to co-produce research; and disseminating research and engaging communities. As defined in this series, co-production is when researchers work together with knowledge users (comprising patients and caregivers, the public, clinicians, policy makers, health system leaders, and others) to identify a problem and produce knowledge, sharing power and responsibility from the start to the end of the research.

\section{Building on established structures and ensuring inclusive representation}

The speed and breadth of the covid-19 pandemic have underscored the need for a rapid co-produced response to create knowledge that can improve interventions. This has resulted in policy makers often collaborating with known researchers and groups who have the capacity to join such a response. For example, while there is no "one way" in which researchers and policy makers interact, there are often established channels, relationships, and structures of collaboration. In Germany, existing structures have been included in the response to the covid-19 pandemic, including scientific advisory boards, professional associations (the Fachgesellschaften), and formal and informal working groups and committees based in universities and research institutes such as the Max Planck Institutes and the national public health institute (the Robert Koch-Institute).
Similarly, since January 2020, policy makers and researchers in Hong Kong have closely collaborated to tackle and respond to the covid-19 crisis. At the political level, Hong Kong's chief executive convened and continues to chair an expert advisory panel under a covid focused steering committee cum command centre. At the operational level, the Department of Health adapted its pre-existing scientific advisory committee to specifically advise on covid-19. These structures are supplemented by frequent outreach by the political and policy establishment to Hong Kong's research community with the relevant expertise to inform policies and covid-19 interventions.

The emerging scientific knowledge on covid-19 has generated much interest in the media and from the public, and this attention has made collaboration more complex and challenging than usual. It has forced policy makers to rethink the formal and informal structures of how, where, when, and with whom they collaborate, including with researchers as well as the broader public, patients, and communities. Beyond existing structures, new structures with improved multistakeholder representation can also create the groundwork to change how knowledge is co-produced. For example, in Pakistan at the start of the pandemic the government adopted a "whole of government" approach with the establishment of a national coordination council chaired by the prime minister with health, finance, planning, defence, and other ministries. A key function of the council was to engage researchers in the national response, including by supporting the generation and use of local evidence and knowledge for strategic decision making.

In April 2020 Germany's National Academy of Sciences convened an expert group, which included philosophers, historians of science, theologians, and jurists to advise the government on how to emerge ethically from the initial shutdowns and loosen its restriction policies. ${ }^{1}$ However, this inclusive approach seems to be an anomaly. A study of 24 countries' 
covid-19 task forces found they mostly comprised politicians, virologists, and epidemiologists, and did not include other relevant health and social experts. There was also a notable exclusion of women. ${ }^{2}$

Although governments have primarily built on existing structures as a starting point for the response, this approach may have excluded some groups and exacerbated the marginalisation of stakeholders who do not have the relationships or resources to engage. Because of the political context as well as power imbalances between and across research institutions, many policy makers and research entities may not be able to pivot and shift long standing structures and practices at short notice. The availability of human and financial resources within research institutions means some are in a better position to respond to the rapidly evolving demands for evidence by policy makers, health and social workers, and the broader public. Policy makers may also depend on existing structures to collaborate with researchers to the detriment of more inclusive structures, such as patients, civil society groups, and communities. ${ }^{3}$

\section{Working together to co-produce research to improve health outcomes}

The scale of the covid-19 pandemic means no single entity can provide the needed support or engage with all the relevant data and possible constituencies. Researchers and policy makers are working together to pool resources, produce knowledge, and develop policy responses. For example, Hong Kong's expert advisory panel, in collaboration with local clinicians and scientists, are jointly providing information on covid-19 directly to the public. Academics at the University of Hong Kong have been estimating and publishing real time results, known as "nowcasting," to help inform how policy makers determine interventions based on risks and how communities and individuals adapt their behaviour, such as social distancing or working from home, in response. ${ }^{45}$ In Pakistan, researchers from the Medical Research Council, the National Institute of Health, and other academic and policy institutions collaborated on a new platform to collect and analyse local data to inform and shape the government's response.

In Lebanon, researchers at the American University of Beirut engaged with the Ministry of Public Health in March 2020 to identify and prioritise needs around covid19 preparedness and response. In close collaboration with policy makers, health workers, municipalities, non-governmental organisations, and communities, researchers produced Lebanon's first national policy document on the pandemic response, reinforcing the need for stricter social distancing measures and to guide hospital and primary healthcare centre preparedness. The pandemic has also presented opportunities for researchers, communities, and public health advocates to shape the policy agenda by bringing pressing but often overlooked issues to the attention of policy makers. As part of efforts to advocate the banning of waterpipe smoking, representatives of the Tobacco Control Coalition in Lebanon underscored the association between covid-19 and waterpipe smoking in a targeted press conference with the head of the parliamentary health committee. In July 2020 the serving of waterpipes was banned in public places.

Researchers, public health specialists, epidemiologists, patients, community members, policy makers, data analysts, and evaluation experts are all generating relevant evidence to inform the covid-19 response. This has produced a massive amount of information. For example, by September 2020, the New England Journal of Medicine had already received more than double the number of submissions it received in $2019 .{ }^{6}$ However, much of this research has been produced in a fragmented way by researchers from a single discipline, and it undermines the efficiency of a collective response. In addition, much of the existing research has focused on the treatment and management of covid-19, while behavioural, environmental, social, and systems research and interventions have been largely overlooked in the covid-19 response.

\section{Disseminating research and engaging communities in the covid-19 response}

Policy makers have needed rapid responses from the scientific community to inform the development of policies and approaches to the pandemic. The pandemic has also created new opportunities for policy makers and researchers to share information with a wider audience. For example, multiple platforms such as social media, emails, television and radio interviews, podcasts, press conferences, and online webinars are used to disseminate research findings. In Germany, as in many countries, academics and scientists have gained national prominence similar to that of media commentators or television personalities. Their straightforward communication style has helped to calm an unsettled public and build trust and understanding about why interventions are needed. Indeed, it has been noted that "scientists who were barely known outside a narrow academic circle are now household names, lauded and vilified in turn in the press and on social media." ${ }^{8}$ The Lebanese policy document on the pandemic response mentioned above was launched in a prime time television interview as well as being shared with parliamentarians, policy makers, and representatives of the covid-19 national committee. Moreover, public awareness of research is increasing and reflects the growing popular interest to engage with, and contest, science in the ongoing covid19 response.

In Pakistan, researchers coordinated broad communication and outreach initiatives with communities and the health workforce through print, electronic, and social media. Policy makers and researchers engaged religious leaders and celebrities as well as government leaders and athletes to share important health information with the broader public. Public audiences are also playing an active part in shaping research and the covid-19 response. For example, there is growing evidence of participatory action research transforming communities' covid-19 responses across regions. ${ }^{9}$ There is also an increasing sense of a "new normal," in which patient voices are integral partners in co-producing the response ${ }^{10}$ and in which new approaches capitalise on online and digital communication to ensure patient engagement. ${ }^{11}$ As a covid-19 vaccine is rolled out, continued community engagement will be crucial and will likely be feasible only with strong community participation. $^{12}$

Given the nature of the pandemic, knowledge, recommendations and advice are constantly evolving, leading to shifts in positions and adaptations in strategy. Such changes can be destabilising and undermine trust in government authorities, even more so in situations of social unrest. ${ }^{13}$ Political and social pressures to communicate information may also run counter to the established culture of research and science, including in the way research is disseminated. The covid19 pandemic has reinforced longstanding tensions within the research community about how best to engage with political stakeholders and share research findings with the public, while also maintaining scientific integrity and independence. 
The pandemic highlights how co-production can help fill the "know-do" gap by accelerating implementation of interventions to tackle the pandemic. For example, Hong Kong's nowcasting effort showcases how science can directly shape and influence both policy interventions and how individuals engage with science and data to understand interventions. Covid19 is transforming how we understand those who are "knowledge users" and those who are "knowledge producers," and this understanding is widening as the pandemic is affecting almost everyone, everywhere.

\section{Conclusion}

The ongoing covid-19 pandemic shows the importance of a co-production approach to decision making that engages policy makers, researchers, communities, and other stakeholders throughout the process. To support a co-production approach, existing structures have been built on and formal and informal alliances have been established in response to the pandemic. However, these efforts and relationships need to be consolidated and institutionalised for policy making. Moving forward, the covid-19 experience has revealed the need for mechanisms to coordinate and build bridges between and across organisations, institutions, and networks for more effective policy responses. It has also reinforced the need to strengthen and institutionalise co-production efforts to promote a more proactive, inclusive, swift, and evidence informed response to future public health crises.

The current and ongoing covid-19 crisis is changing how and when researchers and policy makers collaborate to develop, create, and apply knowledge for policy making and particularly how researchers engage with the broader public. The result for now, however, is that the covid-19 response is often being co-produced by default instead of by design. We must build on the positive signs and opportunities created by the covid-19 response to accelerate further an inclusive shift towards the co-production of evidence based policy making.

Contributors and sources: RM is a health policy and systems researcher at the Alliance for Health Policy and Systems Research. FEJ has research activities, publications, and experience focus on bringing science and evidence to bear on major health system, policy and development efforts in low and middle income countries. He has contributed to the establishment, expansion, or design of different health systems arrangements in different countries. $\mathrm{AH}$ is a public health specialist and an academic with extensive experience at the policy and strategic level planning execution. JH is a health policy and systems analyst by training and leads the Robert Koch Institute's Centre for International Health Protection, including its work on covid-19. GML is an infectious disease epidemiologist who has worked on SARS, influenza, and covid-19. AG leads the Alliance for Health Policy and Systems Research and previously served in several leadership roles in his country's government and in the academy.

Competing interests: We have read and understood BMJ policy on declaration of interests and have no relevant interests to declare.

Provenance and peer review: Commissioned; externally peer reviewed.

This article is part of a series produced in conjunction with the WHO and the Alliance for Health Policy Systems and Research with funding from the Doris Duke Charitable Foundation. The BMJ peer reviewed, edited, and made the decision to publish.

Robert Marten, scientist ${ }^{1}$

Fadi El-Jardali, professor ${ }^{2}$

Assad Hafeez, professor ${ }^{3}$

Johanna Hanefeld, director and associate professor ${ }^{4,5}$

Gabriel M Leung, professor and dean ${ }^{6}$

Abdul Ghaffar, executive director ${ }^{1}$

${ }^{1}$ Alliance for Health Policy and Systems Research, World Health Organization, Geneva, Switzerland

${ }^{2}$ Knowledge to Policy (K2P) Center, Faculty of Health Sciences, American University of Beirut, Beirut, Lebanon

${ }^{3}$ Health Services Academy, Islamabad, Pakistan

${ }^{4}$ Robert Koch-Institute, Berlin, Germany

${ }^{5}$ London School of Hygiene and Tropical Medicine, London, UK

${ }^{6}$ LKS Faculty of Medicine, University of Hong Kong, Hong Kong SAR, China

Correspondence to: R Marten

martenr@who.int

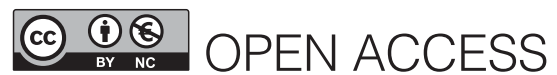

This is an Open Access article distributed under the terms of the Creative Commons Attribution IGO
License (https://creativecommons.org/licenses/ by-nc/3.0/igo/), which permits use, distribution, and reproduction for non-commercial purposes in any medium, provided the original work is properly cited.

\section{Check for updates}

1 Matthews D. German humanities scholars enlisted to end coronavirus lockdown. Times Higher Education 2020 Apr 22. https://www.timeshighereducation. com/news/german-humanities-scholars-enlistedend-coronavirus-lockdown

2 Rajan D, Koch K, Rohrer K, et al. Governance of the Covid-19 response: a call for more inclusive and transparent decision-making. BMJ Glob Health 2020;5:e002655. doi:10.1136/ bmjgh-2020-002655

3 Filipe A, Renedo A, Marston C. The co-production of what? Knowledge, values, and social relations in health care. PLOS Biol 2017;15:e2001403. doi:10.1371/journal.pbio.2001403

4 Wu JT, Leung K, Leung GM. Nowcasting and forecasting the potential domestic and international spread of the 2019-nCoV outbreak originating in Wuhan, China: a modelling study. Lancet 2020;395:689-97. doi:10.1016/S0140 6736(20)30260-9

5 Leung G. Lockdown can't last forever. Here's how to lift it. The New York Times 2020 Apr 6. https://www. nytimes.com/2020/04/06/opinion/coronavirusend-social-distancing.htm

6 Yong Ed. How science beat the virus.Atlantic 2021;/an/Feb. https://www.theatlantic.com/ magazine/archive/2021/01/science-covid-19manhattan-project/617262/.

7 Michie S, West R. Behavioural, environmental, social, and systems interventions against covid-19. BM/ 2020;370:m2982. doi:10.1136/bmj.m2982

8 Riding the coronacoaster of uncertainty. Lancet Infect Dis 2020;20:629. doi:10.1016/S1473 3099(20)30378-9

9 Loewenson R, Colvin C, Rome N, et al. 'We are subjects, not objects in health': Communities taking action on COVID-19. TARSC, 2020.

10 Immonen K. The views of patients and the public should be included in policy responses to covid-19. BMJ Opinion 2020 Mar 30. https://blogs.bmj.com/ bmj/2020/03/30/the-views-of-patients-and-thepublic-should-be-included-in-policy-responses-tocovid-19/

11 Richards T, Scowcroft H, BMJ's international patient and public advisory panel. Patient and public involvement in covid-19 policy making. BMJ 2020;370:m2575. doi:10.1136/bmj.m2575

12 Torreele E. The rush to create a covid-19 vaccine may do more harm than good. BM/ 2020:370:m3209. doi:10.1136/bmj.m3209

13 Ni MY, Yao XI, Leung KSM, et al. Depression and post-traumatic stress during major social unrest in Hong Kong: a 10-year prospective cohort study. Lancet 2020;395:273-84. doi:10.1016/S01406736(19)33160-5

Cite this as: $B M J$ 2021;372:n243 http://dx.doi.org/10.1136/bmj.n243 